The INL is a

U.S. Department of Energy

National Laboratory

operated by

Battelle Energy Alliance

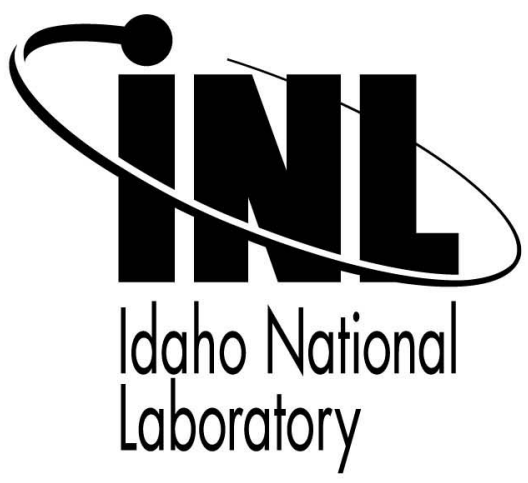

\title{
A Global Approach to the Physics Validation of Simulation Codes for Future Nuclear Systems
}

\section{International Conference on Reactor Physics, Nuclear Power: A Sustainable Resource}

G. Palmiotti

M. Salvatores

G. Aliberti

H. Hiruta

R. McKnight

P. Oblozinsky

W. S. Yang

\section{September 2008}

This is a preprint of a paper intended for publication in a journal or proceedings. Since changes may be made before publication, this preprint should not be cited or reproduced without permission of the author. This document was prepared as an account of work sponsored by an agency of the United States Government. Neither the United States Government nor any agency thereof, or any of their employees, makes any warranty, expressed or implied, or assumes any legal liability or responsibility for any third party's use, or the results of such use, of any information, apparatus, product or process disclosed in this report, or represents that its use by such third party would not infringe privately owned rights. The views expressed in this paper are not necessarily those of the United States Government or the sponsoring agency. 


\title{
A GLOBAL APPROACH TO THE PHYSICS VALIDATION OF SIMULATION CODES FOR FUTURE NUCLEAR SYSTEMS
}

\author{
Giuseppe Palmiottia, Massimo Salvatores ${ }^{\mathrm{a}, \mathrm{b}, \mathrm{c},}, *$, Gerardo Aliberti ${ }^{\mathrm{b}}$, H.Hiruta ${ }^{\mathrm{a}}$, \\ R. McKnight ${ }^{\mathrm{b}}$, P. Oblozinsky ${ }^{\mathrm{d}}$, W.S. Yang ${ }^{\mathrm{b}}$ \\ ${ }^{a}$ Idaho National Laboratory, NSE Division, 2525 Fremont Ave. P.O. Box 1625, Idaho Falls, ID \\ 83415-3855 (USA) \\ ${ }^{\mathrm{b}}$ Argonne National Laboratory, NE Division, Argonne, IL 60439 (USA) \\ ${ }^{c}$ CEA-Cadarache, 13108 St-Paul-Lez-Durance, FRANCE \\ ${ }^{\mathrm{d}}$ Brookhaven National Laboratory (USA) \\ * Corresponding author \\ Massimo.salvatores@cea.fr \\ Tel.: +33442253365, Fax: +33442254142
}

\begin{abstract}
This paper presents a global approach to the validation of the parameters that enter into the neutronics simulation tools for advanced fast reactors with the objective to reduce the uncertainties associated to crucial design parameters. This global approach makes use of sensitivity/uncertainty methods; statistical data adjustments; integral experiment selection, analysis and "representativity" quantification with respect to a reference system; scientifically based cross section covariance data and appropriate methods for their use in multigroup calculations. This global approach has been applied to the uncertainty reduction on the criticality of the Advanced Burner Reactor, (both metal and oxide core versions) presently investigated in the frame of the GNEP initiative. The results obtained are very encouraging and allow to indicate some possible improvements of the ENDF/B-VII data file.
\end{abstract}

\section{Introduction}

Innovative nuclear systems (e.g., as foreseen by Gen-IV, GNEP, or the new fast reactor prototypes planned in France and in Japan, etc.) present new characteristics and requirements both in terms of the reactor cores (e.g., new fuels and structural materials, new core architectures to optimize reactivity coefficients, etc.) and of the associated fuel cycles (e.g., waste minimization, advanced fuel fabrication and reprocessing) that need a specific new effort of validation.

In the case of reactor core, two types of approaches to simulation tools validation can and have been used:

- Mock-up experiments ("global" validation): in this case there is the need for a very close experimental simulation of a reference configuration. Bias factors can be defined but cannot be extrapolated beyond the reference configuration.

- Use of "clean", "representative" integral experiments (usually called "bias factor and adjustment" method). This approach allows defining bias factors, uncertainties and can be used for a wide range of applications. It also allows defining "adjusted" application libraries or even "adjusted" data files.

In the present paper we will present the results of a global data validation and improvement approach, based on generalized 
statistical methods, and making use of new consistent covariance data and of clean integral experiments, selected both on the basis of their "representativity" of the parameters of a reference ABR system (Yang et al., 2008) has been chosen for the present study) and of specific design challenges.

\section{Integral parameter uncertainty reduction}

Recent, extensive sensitivity and uncertainty studies (Aliberti et al., 2006; Salvatores et al., 2007) and the availability of new covariance data (Rochman et al., 2008) have allowed the preliminary quantification of the impact of current nuclear data uncertainties on the design parameters of the major Gen-IV systems, and in particular on Na-cooled fast reactors with different fuels (oxide or metal), fuel composition (e.g., different Pu/TRU ratios) and different conversion ratios.
These studies have pointed out that present uncertainties on the nuclear data should be significantly reduced, in order to get full benefit from advances in modeling and simulation. Only a parallel effort in advanced simulation and in nuclear data improvement will be able to provide designers with more general and well validated calculation tools to meet design target accuracies.

Current and targeted uncertainties for some of the most important SFR design parameters have been assessed (Palmiotti et al., 2006), applicable to the ABR design. A typical example, related to core neutronics, is given in Table 1. This table gives, for each parameter the respective contribution to the current estimated uncertainties of both input data and simulation tools. For the case of $\mathrm{k}_{\text {eff }}$ it takes into account the results of previous work (Salvatores et al., 2008)

Table 1. Current and targeted uncertainties for some SFR design parameters

\begin{tabular}{|c|c|c|c|c|c|c|c|}
\hline \multicolumn{8}{|c|}{ Neutronics: Core } \\
\hline \multirow[b]{2}{*}{ Parameter } & \multicolumn{2}{|c|}{\begin{tabular}{|c|}
$\begin{array}{c}\text { Current uncertainty } \\
\text { (SFR) }\end{array}$ \\
\end{tabular}} & \multirow{2}{*}{$\begin{array}{c}\text { Targeted } \\
\text { Uncertainty }\end{array}$} & \multirow[b]{2}{*}{ Parameter } & \multicolumn{2}{|c|}{$\begin{array}{l}\text { Current uncertainty } \\
\text { (SFR) }\end{array}$} & \multirow[b]{2}{*}{$\begin{array}{c}\text { Targeted } \\
\text { Uncertainty }\end{array}$} \\
\hline & $\begin{array}{c}\text { Input Data } \\
\text { Origin } \\
\text { (A Priori) }\end{array}$ & $\begin{array}{l}\text { Modeling } \\
\text { Origin }\end{array}$ & & & $\begin{array}{l}\text { Input Data } \\
\text { Origin } \\
\text { (A Priori) }\end{array}$ & $\begin{array}{l}\text { Modeling } \\
\text { Origin }\end{array}$ & \\
\hline $\begin{array}{l}\text { Multiplication Factor, } \\
\mathrm{k}_{\mathrm{eff}}(\Delta \mathrm{k} / \mathrm{k})\end{array}$ & $1.5 \%$ & $0.5 \%$ & $0.3 \%$ & $\begin{array}{l}\text { Reactivity Coefficients: } \\
\text { Total }\end{array}$ & $7 \%$ & $15 \%$ & $7 \%$ \\
\hline $\begin{array}{l}\text { Power } \\
\text { Peak }\end{array}$ & $1 \%$ & $3 \%$ & $2 \%$ & $\begin{array}{l}\text { Reactivity Coefficients: } \\
\text { Component }\end{array}$ & $20 \%$ & $20 \%$ & $10 \%$ \\
\hline $\begin{array}{l}\text { Power } \\
\text { Distribution }\end{array}$ & $1 \%$ & $6 \%$ & $3 \%$ & Fast Flux for Damage & $7 \%$ & $3 \%$ & $3 \%$ \\
\hline $\begin{array}{l}\text { Conversion Ratio } \\
\text { (Absolute Value) }\end{array}$ & $5 \%$ & $2 \%$ & $2 \%$ & Kinetics Parameters & $10 \%$ & $5 \%$ & $5 \%$ \\
\hline $\begin{array}{l}\text { Control Rod Worth: } \\
\text { Element }\end{array}$ & $5 \%$ & $6 \%$ & $5 \%$ & $\begin{array}{l}\text { Local Nuclide Densities: } \\
\text { Major }\end{array}$ & $5 \%$ & $3 \%$ & $2 \%$ \\
\hline $\begin{array}{l}\text { Control Rod Worth: } \\
\text { Total }\end{array}$ & $5 \%$ & $4 \%$ & $2 \%$ & $\begin{array}{l}\text { Local Nuclide Densities: } \\
\text { Minor }\end{array}$ & $30 \%$ & $10 \%$ & $10 \%$ \\
\hline $\begin{array}{l}\text { Burnup Reactivity } \\
\text { Swing }(\Delta \mathrm{k} / \mathrm{k})\end{array}$ & $0.7 \%$ & $0.5 \%$ & $0.3 \%$ & $\begin{array}{l}\text { Fuel Decay Heat at } \\
\text { Shutdown }\end{array}$ & $10 \%$ & $3 \%$ & $5 \%$ \\
\hline
\end{tabular}

These tight design target accuracies, justified by economic and safety goals, can only be met if very accurate nuclear data are used for a large number of isotopes, reaction types and energy ranges.

The corresponding required accuracies on the nuclear data have been evaluated for fast reactor designs with a wide range of fuel and coolant types and of different fuel compositions within a NEA-OECD NSC Working group (Salvatores et al., 2008).

\section{The use of integral experiments and new covariance data}

Some of the most important requirements are difficult to meet using only differential experiments, even if innovative experimental techniques are used. The use of integral experiments has been essential in the past to insure enhanced predictions for power fast reactor cores. A pioneer and comprehensive effort has been made within the French nuclear 
program, in particular in order to produce an "adjusted" data library, based on the JEF file data (Fort et al., 1996).

A major drawback of past studies has been the lack of a consistent, scientifically based set of covariance data. The use of "educated guesses" can be sometimes misleading and not always apt to point out unequivocally real issues. For the present work, a combined use of scientifically based covariance data and of selected integral experiments has been made using classical statistical adjustment techniques (Gandini and Petilli, 1973) together with recent developments (Salvatores et al., 2007). These techniques provide adjusted nuclear data for a wide range of applications, together with new, improved covariance data and bias factors (with reduced uncertainties) for the required design parameters, in order to meet target accuracies.

In fact, if we define $B_{p}$ the "a priori" nuclear data covariance matrix, $\mathrm{S}_{\mathrm{B}}$ the sensitivity matrix of the performance parameters $\mathrm{B}\left(\mathrm{B}=1 \ldots \ldots \mathrm{B}_{\mathrm{TOT}}\right)$ to the $\mathrm{J}$ nuclear data, the "a priori" covariance matrix of the performance parameters is given by:

$$
B_{B}=S_{B}^{T} B_{p} S_{B}
$$

It can be shown that, using a set of I integral experiments $\mathrm{A}$, characterized by a sensitivity matrix $\mathrm{S}_{\mathrm{A}}$, besides a set of statistically adjusted cross-section data, a new (“a posteriori”) covariance matrix $\widetilde{\mathrm{B}}_{\mathrm{p}}$ can be obtained (Gandini and Petilli, 1973):

$$
\widetilde{B}_{p}=B_{p}-B_{p} S_{A}\left(S_{A}^{T} B_{p} S_{A}+B_{A}\right)^{-1} S_{A}^{T} B_{p}
$$

where $\mathrm{B}_{\mathrm{A}}$ is the integral experiment uncertainty matrix, $\left(b_{i i}\right.$ are the experimental uncertainties of each experiment i) and $\mathrm{S}_{\mathrm{A}}$ is the sensitivity matrix of the I experiments to the $\mathrm{J}$ nuclear parameters (cross-sections by energy group, isotope, and reaction type).

This matrix can then be used to define a new ("a posteriori") covariance matrix $\widetilde{\mathrm{B}}_{\mathrm{B}}$ for the performance parameters:

$$
\begin{aligned}
\tilde{B}_{B} & =S_{B}^{T} \tilde{B}_{p} S_{B} \\
& =B_{B}-S_{B}^{T} B_{p} S_{A}\left(S_{A}^{T} B_{p} S_{A}+B_{A}\right)^{-1} S_{A}^{T} B_{p} S_{B} \\
& =B_{B}\left\{1-\left(S_{B}^{T} B_{p} S_{B}\right)^{-1}\left(S_{A}^{T} B_{p} S_{A}+B_{A}\right)^{-1}\right. \\
& \left.\times\left(S_{A}^{T} B_{p} S_{B}\right)^{2}\right\}
\end{aligned}
$$

The method can be further improved to "adjust" physical parameters and to obtain in a second phase, a fully "adjusted" data file (D'Angelo et al., 1978). In the present work, we have used the method outlined above, and we have made extensive use of the capability to evaluate "a posteriori" covariance data.

\section{Selection of the reference system and criteria for the choice of integral experiments}

The purpose of this work has been to provide a first series of guidelines to improve methods and data used in the preliminary study of a sodium-cooled fast spectrum "advanced burner" reactor, as defined within the GNEP initiative and the AFCI program (Yang et al., 2008). The reference $1000 \mathrm{MWt}$ ABR core concepts were developed with ternary metal and mixed oxide fuels. Compact core concepts of medium TRU conversion ratio ( $\sim 0.8$ for the startup core and $\sim 0.7$ for the recycled equilibrium core) were developed by trade-off between the burnup reactivity loss and the TRU conversion ratio. Two enrichment zones are used for the metal core, whereas three enrichment zones are used for the oxide core. In both cases, there is a steel reflector surrounding the core and no fertile blanket (Yang et al., 2008).

The selected integral experiments should meet a series of requirements: a) low and well documented experimental uncertainties; b) enabling to separate effects (e.g., capture and fission); and c) allowing validating global energy and space dependent effects.

As for the point b) above, irradiation experiments, in particular of separate isotope samples, allow to have very significant information on capture data, while fission rate experiments in well characterized spectra provide high accuracy information on fission data. As for the point c), the global energy validation should be envisaged using as far as possible "representative" experiments, according to the definition given below, while specific spatial effects (as reflector effects in the ABR cores) should be singled out with appropriate experiments (e.g., experiments with or without blankets, to underline possible specific effects due to the presence of a steel reflector).

In order to use (or plan for) experiments able to reduce uncertainties on selected design parameters (as criticality), a formal approach, initially proposed by Usachev et al. (1978) has 
been applied by Palmiotti and Salvatores (1984) and further developed by Gandini (1988)

In the case of a reference parameter $R$, once the sensitivity coefficient matrix $S_{R}$ and the covariance matrix $\mathrm{D}$ are available, the uncertainty on the integral parameter can be evaluated by the equation:

$$
\Delta R_{0}^{2}=S_{R}^{+} D S_{R}
$$

We can consider an integral experiment conceived in order to reduce the uncertainty $\Delta R_{0}^{2}$. If $\mathrm{S}_{\mathrm{E}}$ is the sensitivity matrix associated with this experiment. We call "representativity factor" the following expression:

$$
r_{R E}=\frac{\left(S_{R}^{+} D S_{E}\right)}{\left[\left(S_{R}^{+} D S_{R}\right)\left(S_{E}^{+} D S_{E}\right)\right]^{1 / 2}}
$$

The uncertainty on the reference parameter $\mathrm{R}$ is reduced by:

$$
\Delta R_{0}^{2}=\Delta R_{0}^{2} \cdot\left(1-r_{R E}^{2}\right)
$$

If more than one experiment is available, the previous equation can be generalized. In the case of two experiments, characterized by sensitivity matrices $S_{\mathrm{E} 1}$ and $\mathrm{S}_{\mathrm{E} 2}$ the following expression can be derived:

$$
\Delta R_{0}^{\prime 2}=S_{R}^{+} D^{\prime} S_{R}=\Delta R_{0}^{2}\left[1-\frac{\left(r_{R 1}-r_{R 2}\right)^{2}}{1-r_{12}^{2}}-\frac{2 r_{R 1} r_{R 2}}{1+r_{12}}\right]
$$

where $\mathrm{D}^{\prime}$ is the new covariance matrix and

$$
\begin{aligned}
& r_{12}=\frac{\left(S_{E 1}^{+} D S_{E 2}\right)}{\left[\left(S_{E 1}^{+} D S_{E 1}\right)\left(S_{E 2}^{+} D S_{E 2}\right)\right]^{1 / 2}} \\
& r_{R 1}=\frac{\left(S_{R}^{+} D S_{E 1}\right)}{\left[\left(S_{R}^{+} D S_{R}\right)\left(S_{E 1}^{+} D S_{E 1}\right)\right]^{1 / 2}} \\
& r_{R 2}=\frac{\left(S_{R}^{+} D S_{E 2}\right)}{\left[\left(S_{R}^{+} D S_{R}\right)\left(S_{E 2}^{+} D S_{E 2}\right)\right]^{1 / 2}}
\end{aligned}
$$

\section{Integral experiment selection}

Table 2 shows the list of significant experiments that have been chosen in the present study together with the main integral parameters that have been measured and that have been calculated. These experiments allow covering a wide range of fuel types, including the reference system fuels (oxide, metal); a wide range of $\mathrm{Pu} /(\mathrm{Pu}+\mathrm{U})$ ratios and corresponding spectrum types (including both fission spectrum-type experiments and softer spectra), separated capture (PROFIL irradiation experiments in PHENIX, D'Angelo et al., 1990) and fission rate effects for TRU (COSMO fission rate experiments, NEA, 2005), combined capture and fission effects (TRAPU irradiated fuels in PHENIX with different $\mathrm{Pu}$ vectors) and finally, reflector vs. blanket effects (ZPR3-53 with blanket and ZPR3-54 with reflector, CIRANO with reflector (Finck, 1996))

Table 2. List of integral experiments to be used in the statistical adjustment

\begin{tabular}{||c||c|c|c|c|c||}
\hline \multirow{2}{*}{ Experiment } & \multicolumn{3}{|c|}{ Parameter to be analyzed } & \multirow{2}{*}{ Fuel Type } & \multirow{2}{*}{ Pu/(U+Pu) } \\
\cline { 2 - 4 } & $\begin{array}{c}\text { Critical } \\
\text { mass }\end{array}$ & $\begin{array}{c}\text { Reaction } \\
\text { Rates }\end{array}$ & $\begin{array}{c}\text { Irradiation } \\
\text { Experiment }\end{array}$ & & \\
\hline \hline GODIVA & Yes & Yes & - & U Metal & 0.0 \\
\hline JEZEBEL $^{239}$ & Yes & Yes & - & Pu Metal & 1.0 \\
\hline JEZEBEL $^{240}$ & Yes & - & - & Pu Metal & 1.0 \\
\hline ZPR-3/53 & Yes & Yes & - & PuC-UC & 0.42 \\
\hline ZPR-3/54 & Yes & Yes & - & PuC-UC & 0.42 \\
\hline ZPPR-15 & Yes & Yes & & $\mathrm{Pu}-U$ Metal $_{n}$ & 0.13 \\
\hline COSMO $^{\mathbf{a}}$ & - & Yes & - & $\mathrm{PuO}_{2}-\mathrm{UO}_{2}$ & 0.27 \\
\hline CIRANO $^{\mathbf{a}}$ & Yes & - s & - & $\mathrm{PuO}_{2}-\mathrm{UO}_{2}$ & 0.27 \\
\hline PROFIL $^{\mathbf{b}}$ & - & - & Yes & $\mathrm{PuO}_{2}-\mathrm{UO}_{2}$ & 0.27 \\
\hline TRAPU $^{\mathbf{b}}$ & - & - & Yes & $\mathrm{PuO}_{2}-\mathrm{UO}_{2}$ & 0.27 \\
\hline \hline
\end{tabular}

a) experiments performed in the MASURCA facility (NEA, 2005)

b) irradiation experiments performed in the PHENIX reactor (D’Angelo, 1990)

As far as representativity, we considered a range of different ZPPR and ZPR experiments, in particular assemblies ZPPR-2, ZPPR-9 and ZPR6-7 with $\mathrm{Pu}$ oxide fuel,
ZPPR-15 with $\mathrm{Pu}$ metal fuel, ZPR6-6 with enriched $\mathrm{UO}_{2}$ fuel. We performed a representativity study on the criticality of these experiments with respect to the two $A B R$ 
cores. We added for comparison purposes, the ZPR3-53 and 54 experiments. The results shown in Table 3 indicate that the ZPPR-15 experiment is the best suited to "represent" both ABR reference cores and that the other cores will not add significant information. In fact if we consider the extra information brought by e.g., ZPPR-9 with respect to ZPPR-15, we find, using the expression (4), that adding ZPPR-9 there is only a very limited impact on the ABR $k_{\text {eff }}$ uncertainty reduction, since the $r_{12}$ value relative to ZPPR15 and ZPPR-9 is too close to 1 (0.978).

Table 3. Representativity factors for $\mathrm{k}_{\text {eff }}$

\begin{tabular}{|c|c|c|}
\hline Experiment & $\begin{array}{c}\text { ABR } \\
\text { Metal }\end{array}$ & $\begin{array}{c}\text { ABR } \\
\text { Oxide }\end{array}$ \\
\hline ZPPR-15 & 0.814 & 0.738 \\
\hline ZPPR-2 & 0.780 & 0.740 \\
\hline ZPPR-9 & 0.796 & 0.723 \\
\hline ZPR3-53 & 0.435 & 0.434 \\
\hline ZPR3-54 & 0.065 & 0.115 \\
\hline ZPR6-6 & 0.190 & 0.175 \\
\hline ZPR6-7 & 0.792 & 0.739 \\
\hline
\end{tabular}

As far as reflector effects, the results of a sensitivity study pointed out that the role of iron cross sections on criticality is much larger for configurations with reflector surrounding directly the core, see Table 4.

Finally, it should be noted that the experiments chosen here to give information on the capture and fission rates of the TRU, were performed or in the PHENIX reactor (PROFIL and TRAPU), or in the MASURCA experiment COSMO, all configurations with a neutron spectrum representative of the $1000 \mathrm{MWt}$ ABR cores, here chosen as reference cores.

Table 4. $\mathrm{K}_{\text {eff }}$ sensitivity (\%) of Fe-56 data

\begin{tabular}{|l|c|r|r|r|r|}
\hline $\begin{array}{c}\text { Experiment/ } \\
\text { Configuration }\end{array}$ & $\begin{array}{c}\text { Blanket (B) } \\
\text { or } \\
\text { Reflector } \\
\text { (R) }\end{array}$ & Capt. & Elast. & Inel. & Total \\
\hline ZPR3-53 & $\mathrm{B}$ & -0.11 & 0.76 & -0.02 & 0.63 \\
\hline ZPR3-54 & $\mathrm{R}$ & -1.40 & 16.5 & 1.50 & 16.6 \\
\hline CIRANO & $\mathrm{R}$ & -1.50 & 6.28 & -0.24 & 4.55 \\
\hline ZPPR-15 & $\mathrm{B}$ & -1.54 & 1.67 & -2.55 & 2.43 \\
\hline ABR-Metal & $\mathrm{R}$ & -1.49 & 3.05 & -3.06 & -1.51 \\
\hline ABR Oxide & $\mathrm{R}$ & -1.73 & 1.79 & -3.29 & -3.23 \\
\hline
\end{tabular}

\section{Methods used for the analysis of experiments, sensitivity, uncertainty and adjustments}

The calculation method used both for the assessment of the integral parameters of the reference systems and for the analysis of the experiments is based on the ENDF/B-VII data file and on the Monte Carlo code MCNP. The sensitivity, uncertainty and representativity analysis have been performed with the codes VARI3D (Adams, 1975) and ERANOS (Rimpault et al., 2002).

As for the statistical data adjustment, new ("a posteriori") uncertainty and covariance data calculation, the methods indicated in Section 3 have been used.

In order to allow a first indication of the potential need for data adjustments and the associated impact on reference systems integral parameters (e.g., $\mathrm{k}_{\text {eff }}$ ), a reduced group structure in four energy "bands" (upper energy: $20 \mathrm{MeV}, 0.5 \mathrm{MeV}, 67 \mathrm{KeV}, 2 \mathrm{KeV}$ ) has been used.

To collapse the original covariance data (indicated as "BOLNA" by Salvatores et al. (2007)) provided in a 15-group structure, a new algorithm (Hikaru et al., 2008) has been used, based on a conservation principle. In particular, the algorithm defines a collapsed covariance data that reproduces the integral parameter uncertainty as calculated with finer group structure covariance data. In fact, the uncertainty on an integral parameter $R_{k}$ is given by:

$$
\Delta R_{k}^{2}=S_{k, I} D_{I} S_{k, I}^{+}
$$

where $D_{I}$ is defined at the fine group level ( $\mathrm{i}=1 \ldots \mathrm{I})$ and the sensitivity vectors $S_{k, I}$ have I components $s_{k, i} \quad(\mathrm{i}=1 \ldots \mathrm{I})$. One can define a broad group grid $(j=1 \ldots \mathrm{J}, \mathrm{J}<<\mathrm{I})$ such that the fine group uncertainty is conserved:

$$
S_{k, J} D_{J}^{k} S_{k, J}^{+} \equiv \Delta R_{k}^{2}
$$

That implies that:

$$
S_{k, J} D_{J}^{k} S_{k, J}^{+}=S_{k, I} D_{I} S_{k, I}^{+}
$$

One can write for each element $d_{j, j^{\prime}}^{k}$ of the matrix $D_{J}^{k}$ :

$$
d_{j, j^{\prime}}^{k}=\frac{\sum_{i \in j} s_{k, i} \sum_{i \in j^{\prime}} d_{i, i^{\prime}}^{k} s_{k, i^{\prime}}^{+}}{s_{k, j} s_{k, j^{\prime}}^{+}}
$$


where $\quad s_{k, j}=\sum_{i \in j} s_{k, i}$ and $s_{k, j}^{+}=\sum_{i \in j} s_{k, i}^{+} \cdot D_{J}^{k}$

is the appropriate broad group covariance matrix, since its use allows the conservation of the uncertainty on the parameter k calculated at the fine group (reference grid) level.

In principle, for each integral parameter $p$ in each configuration (experiment) one should calculate the corresponding "broad" group covariance matrix $D_{J}^{p}$, according to the previous algorithm. However, calculations performed for a number of the configurations of interest in the present study, have shown that the covariance data, collapsed in order to conserve the original uncertainty on the $\mathrm{k}_{\text {eff }}$ of the reference $A B R$ configuration with oxide fuel, allow to reproduce satisfactorily at the 4 energy band level, the $k_{\text {eff }}$ of all the integral experiments chosen in the present study, see Table 5. In the table uncertainties obtained using different sets of sensitivity coefficients (corresponding to the different systems) are compared against the reference BOLNA 15group results.

Table 5. Uncertainties calculated collapsing 15 group sensitivity coefficient sets.

\begin{tabular}{|c|c|c|c|c|c|c|c|c|c|c|}
\hline & \multicolumn{8}{|c|}{ Reactor sensitivity coefficient set used to calculate the 4-group covariance matrix } \\
\cline { 2 - 11 } Reactor & Reference & $\begin{array}{c}\text { ABR- } \\
\text { Oxide }\end{array}$ & $\begin{array}{c}\text { ABR- } \\
\text { Metal }\end{array}$ & $\begin{array}{c}\text { ZPPR- } \\
15 A\end{array}$ & $\begin{array}{c}\text { ZPPR- } \\
2\end{array}$ & $\begin{array}{c}\text { ZPPR- } \\
9\end{array}$ & $\begin{array}{c}\text { ZPR3- } \\
53\end{array}$ & $\begin{array}{c}\text { ZPR3- } \\
54\end{array}$ & $\begin{array}{c}\text { ZPR6- } \\
6 \mathrm{~A}\end{array}$ & $\begin{array}{c}\text { ZPR6- } \\
7\end{array}$ \\
\hline ABR-Oxide & 0.0144 & 0.0144 & 0.0145 & 0.0142 & 0.0145 & 0.0136 & 0.0450 & 0.0121 & 0.0104 & 0.0141 \\
\hline ABR-Metal & 0.0147 & 0.0146 & 0.0147 & 0.0146 & 0.0147 & 0.0142 & 0.0563 & 0.0126 & 0.0127 & 0.0146 \\
\hline ZPPR-15A & 0.0101 & 0.0100 & 0.0100 & 0.0101 & 0.0102 & 0.0100 & 0.0350 & 0.0090 & 0.0098 & 0.0100 \\
\hline ZPPR-2 & 0.0093 & 0.0091 & 0.0091 & 0.0092 & 0.0093 & 0.0091 & 0.0281 & 0.0083 & 0.0084 & 0.0091 \\
\hline ZPPR-9 & 0.0125 & 0.0125 & 0.0124 & 0.0127 & 0.0128 & 0.0125 & 0.0522 & 0.0111 & 0.0131 & 0.0127 \\
\hline ZPR3-53 & 0.0087 & 0.0084 & 0.0081 & 0.0082 & 0.0082 & 0.0083 & 0.0087 & 0.0086 & 0.0064 & 0.0083 \\
\hline ZPR3-54 & 0.0114 & 0.0110 & 0.0109 & 0.0111 & 0.0097 & 0.0110 & 0.0152 & 0.0113 & 0.0094 & 0.0109 \\
\hline ZPR6-6A & 0.0237 & 0.0236 & 0.0234 & 0.0235 & 0.0236 & 0.0236 & 0.0283 & 0.0234 & 0.0237 & 0.0236 \\
\hline ZPR6-7 & 0.0104 & 0.0104 & 0.0103 & 0.0104 & 0.0105 & 0.0103 & 0.0356 & 0.0094 & 0.0101 & 0.0104 \\
\hline
\end{tabular}

\section{Analysis of the results}

Table 6 gives the $\mathrm{C} / \mathrm{E}$ values with associated uncertainties before and after adjustment for the 44 integral experiments used in this study. The first remark is that ENDF/B-VII performs in general rather well. However, for a number of parameters (higher $\mathrm{Pu}$ isotopes and some minor actinides) there is a clear need of substantial improvements. After adjustment, the "a posteriori" $\mathrm{C} /$ Es show a definite improvement (see Table 6) and with a few exceptions, all residual calculation vs. experiment discrepancies are reduced within the "a posteriori" experimental uncertainties. To obtain this result and in order to obtain a statistically sound adjustment (i.e., as indicated by a $\chi^{2}$ test), it has been necessary in very few cases to modify (i.e., increase) the diagonal uncertainty values of the BOLNA covariance matrix for a specific reaction of a specific isotope. This has been the case for the following data:

Pu-238 capture group 2: from $11.5 \%$ to $50 \%$

$\mathrm{Pu}-238$ capture group 3: from $16.3 \%$ to $50 \%$

$\mathrm{Pu}-238$ capture group 4 : from $3.1 \%$ to $50 \%$
Pu-239 (n, 2n): from $10 \%$ to $30 \%$

Cm-242 capture group 2: from $19.5 \%$ to $100 \%$ Cm-242 capture group 3: from $15.2 \%$ to $100 \%$ $\mathrm{Cm}-242$ capture group 4 : from $5.2 \%$ to $100 \%$

Using these modified data inside BOLNA, it is possible to achieve a $\chi^{2}=80$ for 61 parameters to be adjusted.

Moreover, a closer inspection to the consistency of integral data results has shown that two PROFIL experiments (capture PU241 and -242) are probably affected by some systematic error. In fact, if these two experiments are eliminated, the $\chi^{2}$ is definitely improved $\left(\chi^{2}=50\right)$ and more consistent with the number of parameters to be adjusted (61).

Table 7 gives the final data adjustments for the different isotopes and reactions in the four energy group structure. Among the largest adjustments, there are the $\mathrm{Pu}-238$ capture below $500 \mathrm{KeV}$ and the $\mathrm{Cm}-242$ capture, also below $500 \mathrm{KeV}$.

Inspection of Figs 1 and 2, where different files are compared for these reactions, shows that the large adjustments observed for the ENDF/B-VII Pu-238 and Cm-242 capture data seem to be rather well justified, in particular for $\mathrm{Cm} 242$ capture, for which the ENDF/B- 
VII files show an unphysical discontinuity in the very region where the adjustment has been required to get consistency between calculation and experiment.

Table 6. $\mathrm{C} / \mathrm{E}$ and Associated Uncertainties $(\sigma)$ Before and After Adjustment

\begin{tabular}{|c|c|c|c|c|c|}
\hline Type of Experiment & old $\mathbf{C} / \mathbf{E} \pm \sigma$ & new $\mathbf{C} / \mathbf{E} \pm \sigma$ & Type of Experiment & old $\mathbf{C} / \mathbf{E} \pm \sigma$ & new $\mathbf{C} / \mathbf{E} \pm \sigma$ \\
\hline $\begin{array}{l}\text { U235 Capture } \\
\text { PROFIL1 (a) }\end{array}$ & $0.977 \pm 0.020$ & $1.009 \pm 0.009$ & $\begin{array}{c}\mathrm{Cm} 244 \\
\text { TRAPU2 } \\
\end{array}$ & $0.872 \pm 0.023$ & $0.978 \pm 0.021$ \\
\hline $\begin{array}{l}\text { U238 Capture } \\
\text { PROFIL1 }{ }^{\text {(a) }}\end{array}$ & $1.004 \pm 0.023$ & $1.005 \pm 0.010$ & $\begin{array}{c}\text { U238 Fission Rate } \\
\text { COSMO }^{(\mathrm{c})}\end{array}$ & $0.988 \pm 0.015$ & $1.006 \pm 0.010$ \\
\hline $\begin{array}{l}\text { Pu238 Capture } \\
\text { PROFIL2 }\end{array}$ & $1.744 \pm 0.040$ & $1.015 \pm 0.036$ & $\begin{array}{l}\text { Np237 Fission Rate } \\
\text { COSMO }^{(\mathrm{c})}\end{array}$ & $0.960 \pm 0.015$ & $0.979 \pm 0.011$ \\
\hline $\begin{array}{l}\text { Pu239 (N,2N) } \\
\text { PROFIL1 }\end{array}$ & $0.752 \pm 0.150$ & $0.949 \pm 0.133$ & $\begin{array}{l}\text { Pu238 Fission Rate } \\
\text { COSMO }^{(\mathrm{c})}\end{array}$ & $1.083 \pm 0.025$ & $1.005 \pm 0.023$ \\
\hline $\begin{array}{l}\text { Pu239 Capture } \\
\text { PROFIL1 }{ }^{\text {a) }}\end{array}$ & $0.963 \pm 0.030$ & $1.021 \pm 0.015$ & $\begin{array}{l}\text { Pu239 Fission Rate } \\
\text { COSMO }^{(\mathrm{c})}\end{array}$ & $0.983 \pm 0.013$ & $0.984 \pm 0.003$ \\
\hline $\begin{array}{l}\text { Pu240 Capture } \\
\text { PROFIL1 }^{\text {(a) }}\end{array}$ & $1.001 \pm 0.022$ & $0.995 \pm 0.013$ & $\begin{array}{c}\text { Pu240 Fission Rate } \\
\text { COSMO }^{(\mathrm{c})}\end{array}$ & $1.034 \pm 0.023$ & $1.016 \pm 0.016$ \\
\hline $\begin{array}{l}\text { Pu241 Capture } \\
\text { PROFIL1 }\end{array}$ & $0.847 \pm 0.041$ & $0.871 \pm 0.013$ & $\begin{array}{l}\text { Pu241 Fission Rate } \\
\text { COSMO }^{(\mathrm{c})}\end{array}$ & $0.998 \pm 0.020$ & $1.013 \pm 0.017$ \\
\hline $\begin{array}{l}\text { Pu242 Capture } \\
\text { PROFIL1 }\end{array}$ & $1.092 \pm 0.035$ & $1.128 \pm 0.019$ & $\begin{array}{l}\text { Pu242 Fission Rate } \\
\text { COSMO }^{(c)}\end{array}$ & $1.000 \pm 0.023$ & $1.002 \pm 0.022$ \\
\hline $\begin{array}{l}\text { Am241 Capture } \\
\text { PROFIL1 }\end{array}$ & $1.000 \pm 0.020$ & $1.003 \pm 0.015$ & $\begin{array}{c}\text { Am241 Fission Rate } \\
\text { COSMO }^{(\mathrm{c})}\end{array}$ & $1.074 \pm 0.023$ & $1.003 \pm 0.022$ \\
\hline $\begin{array}{l}\text { Np237 Capture } \\
\text { PROFIL2 }{ }^{\text {(a) }}\end{array}$ & $0.988 \pm 0.036$ & $1.009 \pm 0.022$ & $\begin{array}{c}\text { Am243 Fission Rate } \\
\text { COSMO }^{(\mathrm{c})}\end{array}$ & $1.059 \pm 0.023$ & $1.008 \pm 0.021$ \\
\hline $\begin{array}{c}\text { U236 } \\
\text { TRAPU2 } \\
\end{array}$ & $0.965 \pm 0.010$ & $0.995 \pm 0.009$ & $\begin{array}{c}\mathrm{k}_{\text {eff }} \\
\text { GODIVA }^{(\mathrm{d})}\end{array}$ & $1.000 \pm 0.001$ & $0.999 \pm 0.001$ \\
\hline $\begin{array}{c}\text { Np237 } \\
\text { TRAPU2 }^{(b)}\end{array}$ & $0.880 \pm 0.033$ & $0.954 \pm 0.026$ & $\begin{array}{l}\text { U238 Fission Rate } \\
\text { GODIVA }^{(\mathrm{d})}\end{array}$ & $0.955 \pm 0.012$ & $0.965 \pm 0.004$ \\
\hline $\begin{array}{c}\text { Pu238 } \\
\text { TRAPU2 } \\
\end{array}$ & $0.942 \pm 0.010$ & $1.000 \pm 0.006$ & $\begin{array}{l}\text { Np237 Fission Rate } \\
\text { GODIVA }^{(\mathrm{d})}\end{array}$ & $0.991 \pm 0.016$ & $1.003 \pm 0.010$ \\
\hline $\begin{array}{c}\text { Pu239 } \\
\text { TRAPU2 }\end{array}$ & $1.006 \pm 0.005$ & $1.001 \pm 0.004$ & $\begin{array}{l}\text { Pu239 Fission Rate } \\
\text { GODIVA }^{(\mathrm{d})}\end{array}$ & $0.986 \pm 0.017$ & $0.987 \pm 0.003$ \\
\hline $\begin{array}{c}\text { Pu240 } \\
\text { TRAPU2 }\end{array}$ & $0.982 \pm 0.006$ & $1.000 \pm 0.006$ & $\begin{array}{c}\mathrm{k}_{\text {eff }} \\
\text { JEZEBEL9 }^{(\mathrm{e})}\end{array}$ & $1.000 \pm 0.002$ & $1.001 \pm 0.001$ \\
\hline $\begin{array}{c}\text { Pu241 } \\
\text { TRAPU1 }^{(b)}\end{array}$ & $1.005 \pm 0.006$ & $1.001 \pm 0.003$ & $\begin{array}{l}\text { U238 Fission Rate } \\
\text { JEZEBEL9 }^{(\mathrm{e})}\end{array}$ & $0.974 \pm 0.009$ & $0.984 \pm 0.004$ \\
\hline $\begin{array}{c}\text { Pu242 } \\
\text { TRAPU1 } \\
\end{array}$ & $0.998 \pm 0.008$ & $1.012 \pm 0.004$ & $\begin{array}{l}\text { Np237 Fission Rate } \\
\text { JEZEBEL9 }^{(\mathrm{d})}\end{array}$ & $1.009 \pm 0.017$ & $1.021 \pm 0.010$ \\
\hline $\begin{array}{c}\text { Am241 } \\
\text { TRAPU2 } \\
\end{array}$ & $0.985 \pm 0.039$ & $0.986 \pm 0.005$ & $\begin{array}{c}\mathrm{k}_{\mathrm{eff}} \\
\text { JEZEBEL0 }^{(\mathrm{e})}\end{array}$ & $1.000 \pm 0.002$ & $0.999 \pm 0.002$ \\
\hline $\begin{array}{c}\text { Am242 } \\
\text { TRAPU2 }^{(b)} \\
\end{array}$ & $1.029 \pm 0.043$ & $1.032 \pm 0.013$ & $\begin{array}{c}\mathrm{k}_{\mathrm{eff}} \\
\text { CIRANO }^{(\mathrm{f})} \\
\end{array}$ & $1.007 \pm 0.002$ & $1.002 \pm 0.001$ \\
\hline $\begin{array}{c}\text { Am243 } \\
\text { TRAPU1 }\end{array}$ & $0.939 \pm 0.026$ & $0.974 \pm 0.020$ & $\begin{array}{c}\mathrm{k}_{\text {eff }} \\
\text { ZPPR-15 }\end{array}$ & $0.999 \pm 0.002$ & $0.999 \pm 0.001$ \\
\hline $\begin{array}{c}\text { Cm242 } \\
\text { TRAPU1 }^{(\mathrm{b})} \\
\end{array}$ & $1.003 \pm 0.039$ & $0.971 \pm 0.013$ & $\begin{array}{c}\mathrm{k}_{\text {eff }} \\
\text { ZPR-3/53 }\end{array}$ & $1.009 \pm 0.002$ & $1.001 \pm 0.001$ \\
\hline $\begin{array}{c}\text { Cm243 } \\
\text { TRAPU2 }^{(b)}\end{array}$ & $0.462 \pm 0.031$ & $0.999 \pm 0.031$ & $\begin{array}{c}\mathrm{k}_{\text {eff }} \\
\text { ZPR-3/54 }\end{array}$ & $1.008 \pm 0.002$ & $1.000 \pm 0.001$ \\
\hline
\end{tabular}

(a) Isotope $\mathrm{A} / \mathrm{B}$ atom density ratio at the end of irradiation of a sample of isotope $\mathrm{A}$

(b) Isotope atom density at the end of irradiation of TRAPU fuel pins with different initial Pu vectors.

(c) Normalized fission rates and $\mathrm{k}_{\mathrm{eff}}$ in the COSMO critical experiment at MASURCA.

(d) JEZEBEL9: Pu-239 Sphere.

(e) JEZEBEL0: Pu-239 Sphere with high Pu-240 content.

(f) $\mathrm{k}_{\mathrm{eff}}$ of the critical experiment CIRANO (high Pu content) at MASURCA 
Table 7. Calculated Adjusted Data Change and Original and Adjusted Standard Deviation (\%)

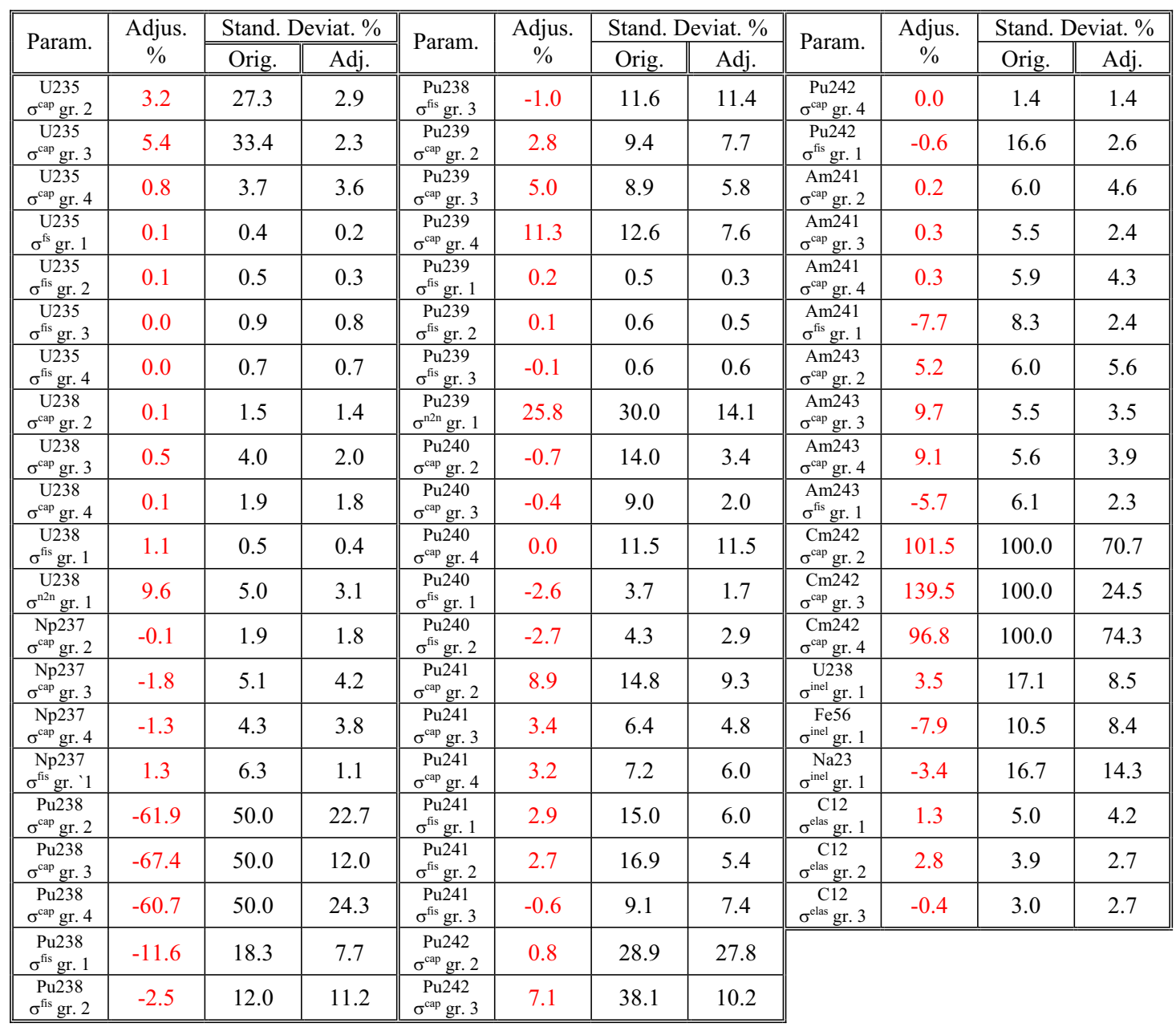

Fig. 1. Pu238 Capture cross section. Red: ENDF/B-VII, Green: JENDL 3.3, Blue: JEF 2.2

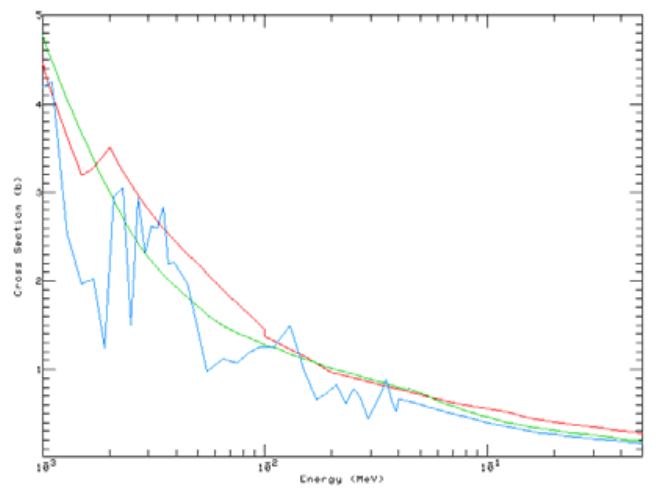

Fig. 2. Cm242 Capture cross section. Red: ENDF/B-VII, Green: JENDL 3.3, Blue: JEF 2.2

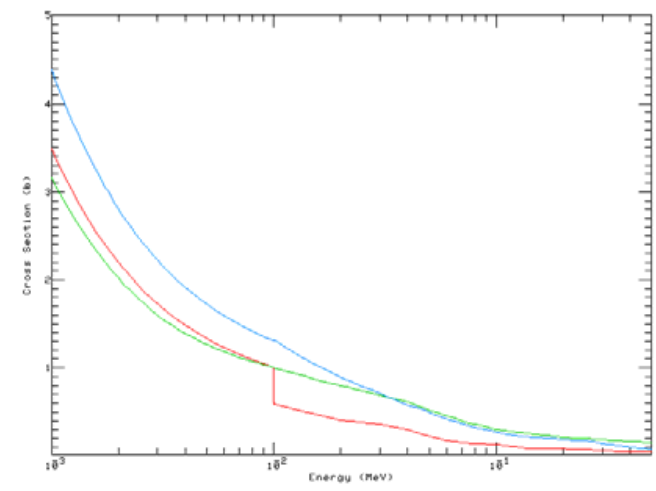


Among the other significant results, it is worthwhile to note that, beside the adjustment itself, the original uncertainties have been drastically reduced. This is the case, for example, of the capture of U-235, and the fission of $\mathrm{Pu}-238$ and $\mathrm{Pu}-242$ above threshold.

As already remarked by the study of the NEA Expert Group (Salvatores et al., 2008), the data of Pu-239 and, to a certain extent, U238 play a very limited role, due to the fact that the uncertainty data for most data of these isotopes in BOLNA, are relatively small. The largest modifications are found for the $\mathrm{Pu}-239$ capture.

Another significant result is the sizable modifications proposed for the $(n, 2 n)$ data of both $\mathrm{Pu}-239$ and U-238.

Finally, as far as minor actinide data, the largest adjustments are found for some fission cross sections (Am-241 and Am-243) and capture cross sections (Am-243)

Important complementary information comes from the "a posteriori" correlations among integral experiments (initially not considered). As an example, pertinent correlations are found between the ZPPR-15 $\mathrm{k}_{\text {eff }}$ and a number of PROFIL data and the $\mathrm{k}_{\mathrm{eff}}$ of other related configurations (see Table 8).

Table 8. ZPPR-15 correlation with other experiments after adjustment

\begin{tabular}{||l|c||}
\hline \multicolumn{1}{|c|}{ Type of Experiment } & Correlation \\
\hline \hline U-238 Capture, PROFIL1 & -0.221 \\
\hline Pu-240 Capture, PROFIL1 & 0.106 \\
\hline Pu-239, TRAPU2 & -0.209 \\
\hline U-238 Fission Rate, COSMO & 0.180 \\
\hline Np-237 Fission Rate, COSMO & 0.115 \\
\hline Pu-241 Fission Rate, COSMO & 0.200 \\
\hline Np-237 Fission Rate, GODIVA & -0.068 \\
\hline Np-237 Fission Rate, JEZEBEL9 & -0.067 \\
\hline $\mathrm{k}_{\text {eff }}$, CIRANO & 0.297 \\
\hline $\mathrm{k}_{\text {eff }}$ ZPR-3/53 & 0.081 \\
\hline $\mathrm{k}_{\text {eff }}$ ZPR-3/54 & -0.052 \\
\hline
\end{tabular}

We have also applied the new cross section covariance matrix to evaluate the "a posteriori" uncertainty on the $\mathrm{k}_{\mathrm{eff}}$ of the two reference systems (ABR with metal or oxide fuel). The results are given in Table 9. The uncertainty on the $\mathrm{k}_{\text {eff }}$ of two reference $\mathrm{ABR}$ configurations are reduced significantly, from $\sim 1.5 \%$ to $\sim 0.6 \%$ in both cases. If we compare with the target accuracy indicated in Table 1, we see that one is now much closer to the target value $(0.3 \%)$. However, it is still necessary to reduce both the method related uncertainty and the residual uncertainty due to nuclear data. As for method uncertainty reduction, current efforts in the field of high fidelity simulation have as target an uncertainty of $\sim 0.1 \%$. As for the nuclear data related uncertainty it is possible to further reduce the value obtained here $(\sim 0.6 \%)$, by including in the adjustment more nuclear data (e.g. more structural material data) and including few more integral experiments, carefully selected for that purpose and using more extensively the "representativity" approach outlined previously.

Table 9. $K_{\text {eff }}$ Uncertainties $[\mathrm{pcm}]$ calculated with BOLNA and Adjusted covariance

\begin{tabular}{|c||c|c|}
\hline Reactor & $\begin{array}{c}\text { BOLNA 4 } \\
\text { groups }\end{array}$ & $\begin{array}{c}\text { Adjusted } \\
\text { Covariance }\end{array}$ \\
\hline \hline ABR Oxide & 1438.7 & 639.1 \\
\hline ABR Metal & 1460.4 & 638.7 \\
\hline
\end{tabular}

Finally, it is interesting to note that the proposed adjustment will reduce uncertainties not only of the $\mathrm{k}_{\text {eff }}$, but also uncertainties on the local TRU nuclide densities after irradiation and, as a consequence, the uncertainty on the reactivity loss per cycle. The explicit verification of these points, as well as the evaluation of the impact of the present adjustments on other ABR integral parameters (e.g., reactivity coefficients) will be performed as part of future work in this field.

\section{Conclusions}

We have outlined a global approach to the validation of the parameters that enter into the neutronics simulation tools for advanced fast reactors with the objective to reduce the uncertainties associated to crucial design parameters. This global approach makes use of sensitivity/uncertainty methods, statistical data adjustments, integral experiment analysis and "representativity" quantification with respect to a reference system, scientifically based cross section covariance data and appropriate methods for their use in multigroup calculations. This global approach has been applied to the uncertainty reduction on the criticality of the Advanced Burner Reactor, (both metal and oxide core versions) presently 
investigated in the frame of the GNEP initiative. The results of this first study have pointed out to a number of physics effects of interest, and have also indicated possible improvements, to be explored in future more detailed studies. Nevertheless, it is remarkable that already at this stage it has been possible to indicate a few significant improvements of the present ENDF/B-VII data file, that have as consequence to reduce by more than a factor of two the present uncertainty, e.g., of the ABR cores $k_{\text {eff }}$ and that improve significantly the prediction of TRU nuclide densities during the cycle.

\section{References}

Adams, C. H., 1975. "Specifications for VARI3D A Multidimensional Reactor Design Sensitivity Code," FRA-TM-74, Argonne National Laboratory.

Aliberti, et al, 2006. "Nuclear Data Sensitivity, Uncertainty and Target Accuracy Assessment for Future Nuclear Systems," Annals of Nuclear Energy, 33, 700-733.

D’Angelo, A., Oliva, A., Palmiotti, G., Salvatores, M., Zero, S., 1978. "Consistent Utilization of Shielding Benchmark Experiments," Nucl. Sci. Eng., 65, 477.

D’Angelo A., Cleri, F., Marimbeau, P., Salvatores, M., and. Grouiller, J. P., 1990. "Analysis of Sample and Fuel Pin Irradiation in PHENIX for Basic Nuclear Data Validation", Nucl. Sci. and Eng. 105, 244.

Finck, P. J et al., 1996. "The CIRANO Experimental Program in Support of Advanced Fast Reactor Physics," International Conference on the Physics of Reactors, PHYSOR'96, Mito, Japan, September 16-20.

Fort, E. et al., 1996. "Realization and Performance of the Adjusted Nuclear Data Library ERALIB1 for Calculating Fast Reactor Neutronics," PHYSOR'96, Mito, Japan, September 16-20.

Gandini, A., Petilli, M., 1973. "AMARA: A Code Using the Lagrange Multipliers Methods of Nuclear Data Adjustment," RT/FI(73)39, Comitato Nazionale per l'Energia Nucleare.

Gandini, A., 1988. "Uncertainty Analysis and Experimental Data Transposition Methods in Uncertainty Analysis," Y. Ronen, Editor, CRC Press.
Hiruta, H., Palmiotti, G., Salvatores, M., Arcilla., R. Jr,. Oblozinsky, P., 2008. "Few group collapsing of covariance matrix data based on a conservation principle," to be presented at Workshop on Neutron Cross Section Covariances, Port Jefferson, 24-27.

NEA, 2005. "Benchmark on Computer Simulation of MASURCA Critical and Subcritical Experiments", NEA/NSC/DOC(2005)23

Palmiotti, et al., May 2006. "Requirements for Advanced Simulation of Nuclear Reactor and Chemical Separation Plants," ANLAFCI-168, Argonne National Laboratory.

Palmiotti, G., Salvatores, M., 1984. "Use of Integral Experiments in the Assessment of Large Liquid-Metal Fast Breeder Reactor Basic Design Parameters," Nucl. Sci. Eng. 87, 333.

Rimpault, G., et al., 2002. "The ERANOS Code and Data System for Fast Reactor Neutronic Analyses," PHYSOR 2002 Conference, Seoul, Korea, October 7-10.

Rochman, D., Herman, M., Oblozinsky, P., and. Mughabghab, S. F., 2007 "Preliminary Cross-Section Covariances for WPEC Subgroup 26," Tech. Rep. BNL-774072007-IR, Brookhaven National Laboratory.

Salvatores, M., Aliberti, G., Palmiotti,, G., 2007. "Nuclear Data Needs for Advanced Reactor Systems. A NEA Nuclear Science Committee Initiative," ND 2007: International Conference on Nuclear Data for Science and Technology, Nice, France, April 22-27.

Salvatores M., Aliberti, G., Palmiotti, G. 2007. "Nuclear Data Validation and Fast Reactor Design Performances Uncertainty Reduction," Trans. ANS Meeting, 96, 519, Boston, Massachusetts, June 22-26.

Salvatores M. Et al., 2008. "OECD/NEA WPEC Subgroup 26 Final Report: Uncertainty and Target Accuracy Assessment for Innovative Systems Using Recent Covariance Data Evaluations," OECD-NEA Report to be published

Usachev, L.N., et al., 1978. Proc. Int. Conf. Neutron Physics and Other Applied Purposes, Harwell, September 25-29, 1978, CONF-780921, p. 181, International Atomic Energy Agency .

Yang, W. S., Kim, T. K., and Hill, R. N., 2008. "Performance Characteristics of Metal and Oxide Fuel Cores for a $1000 \mathrm{MWt}$ Advanced Burner Reactor," ARWIF2008, Fukui, Japan, February 20-22. 